\title{
Effect of carboxymethylcellulose on colloidal properties of calcite suspensions in drilling fluids
}

\author{
Keila Regina Santana Fagundes¹, Railson Carlos da Souza Luz'1, Fabio Pereira Fagundes² \\ and Rosangela de Carvalho Balaban ${ }^{1 *}$
}

\author{
'Laboratório de Pesquisa em Petróleo - LAPET, Instituto de Química - IQ, Centro de Ciências Exatas e da \\ Terra - CCET, Universidade Federal do Rio Grande do Norte - UFRN, Natal, RN, Brasil \\ ${ }^{2}$ Universidade Potiguar - UnP, Natal, RN, Brasil \\ *rosangelabalaban@hotmail.com
}

\begin{abstract}
Drilling fluids are multicomponent systems used to aid the removal of cuttings from a borehole, and subject to a number of requirements to ensure a safe drilling operation. One of the most important is to form a low permeability cake on the walls of the hole penetrated by the bit, to avoid excessive filtrate loss. To that end, carboxymethylcellulose (CMC) associated with calcite $\left(\mathrm{CaCO}_{3}\right)$ can be used. In this paper, the effect of carboxymethylcellulose on the colloidal properties of calcite suspensions in brine was systematically evaluated by rheological properties, filtrate volume and zeta potential. Higher viscosity fluids, lower filtrate loss and less negative zeta potential were obtained using small calcite particles with wide size distribution and CMC with high average molecular weight $(\mathrm{Mw})$ and low average degree of substitution (DS), highlighting the importance of effective interactions between CMC and calcite to improve drilling fluid properties.
\end{abstract}

Keywords: calcite, $\mathrm{CaCO}_{3}, \mathrm{CMC}$, drilling fluids, filtrate loss.

\section{Introduction}

Carboxymethycellulose (CMC) is one of the most important derivatives of cellulose, primarily due to its versatility as thickener, binding agent, emulsifier and stabilizer. The presence of $-\mathrm{CH}_{2}-\mathrm{COO}^{-} \mathrm{Na}^{+}$substituent groups on the cellulose backbone is responsible for higher solubility in aqueous media ${ }^{[1]}$. Polymer concentration ${ }^{[2]}$, salt content ${ }^{[3,4]}$, $\mathrm{pH}^{[5]}$, the presence of surfactant ${ }^{[6]}$, molecular structure ${ }^{[7]}$, $\mathrm{Mw}^{[8]}$ and $\mathrm{DS}^{[9]}$ exert important effects on $\mathrm{CMC}$ solution properties. This polysaccharide has been used in a wide range of applications in foods ${ }^{[10]}$, pharmaceutical products ${ }^{[1]}$, biomaterials $^{[12]}$, cosmetics and electronic devices ${ }^{[13]}$, as well as in many oilfield operations, including drilling fluids ${ }^{[14,15]}$.

In most water-based drilling fluids, $\mathrm{CMC}$ is commonly used in association with calcite (calcium carbonate, $\mathrm{CaCO}_{3}$ ) particles to reduce fluid loss to the surrounding formation ${ }^{[16]}$. However, another important function of water soluble polymers is to provide rheological properties capable of maintaining the cuttings in suspension during drilling operations. As such, it is essential to correlate the polymer chemical structure (DS, Mw and distribution of substituent) with the physical-chemical properties of $\mathrm{CaCO}_{3}$ suspensions, in order to obtain the best result at the lowest cost.

Proper selection of $\mathrm{CMC}$ and $\mathrm{CaCO}_{3}$ can minimize fluid filtration across the wellbore, when a thin low-permeability filter cake is formed. According to the literature, CMC adsorption onto solid substrates is strongly dependent on adsorption kinetics, the $\mathrm{pH}$ of the medium and apparent hydrodynamic thickness ${ }^{[17]}$. Moreover, it also depends on the $\mathrm{Mw}$ and DS of $\mathrm{CMC}^{[18]}$. Caraschi and Campana ${ }^{[1]}$ investigated

the influence of DS of CMC and substituent distribution profile on equilibrium properties in an aqueous medium. It was observed that the stability of aggregates is strongly influenced by the nature of group interactions $(-\mathrm{COOH}$ and $-\mathrm{OH})$, reconstituted bonds and electrostatic repulsions between the charged groups $\left(\mathrm{COO}^{-}\right)$. Backfolk et al. ${ }^{[16]}$ showed the adsorption and association mechanisms for $\mathrm{CMC}$ and $\mathrm{CaCO}_{3}$ suspensions through adsorption isotherms. They concluded that the interactions between CMC and $\mathrm{CaCO}_{3}$ are related to the amount of Lewis acid sites on $\mathrm{CaCO}_{3}$, leading to the formation of $\mathrm{CMC}^{-} \mathrm{Ca}^{2+}$ complexes. Laskowski et al. ${ }^{[19]}$ investigated polysaccharide adsorption onto mineral solid surfaces. The interactions were dependent on the basic/acid features of the hydroxylated metallic sites, which are anchored to the mineral surface. Moreover, the authors reported that hydroxyl and carboxylate groups on CMC have a significant impact on how this polysaccharide adsorbs at the mineral/aqueous solution interface. Some researchers have proposed that the mechanisms responsible for polymer adsorption onto mineral surfaces include hydrophobic interaction ${ }^{[20]}$, hydrogen bounding ${ }^{[21,22]}$, as well as chemical and electrostatic interactions ${ }^{[23]}$.

In the context of complex multicomponent drilling fluids, the adsorption mechanisms of $\mathrm{CMC}$ onto $\mathrm{CaCO}_{3}$, as well as the corresponding effects on fluid properties, have not been clearly elucidated. As such, the aim of this paper is to evaluate the influence of the DS and Mw of CMC on the colloidal properties of $\mathrm{CaCO}_{3}$ suspensions, through rheological properties, filtrate loss and zeta potential. 


\section{Materials and Methods}

\subsection{Materials}

The following products were donated by PETROBRAS S.A.: xanthan gum, sodium chloride and calcium carbonate (calcite) of different particle sizes. CMC sodium salt, with a nominal DS/Mw of $0.7 / 2.5 \times 10^{5} \mathrm{~g} / \mathrm{mol}, 1.2 / 2.5 \times 10^{5} \mathrm{~g} / \mathrm{mol}$ and $0.7 / 0.9 \times 10^{5} \mathrm{~g} / \mathrm{mol}$ were purchased from SIGMAALDRICH.

\subsection{Characterization of $\mathrm{CaCO}_{3}$}

The average particle diameter and particle size distribution curve for $\mathrm{CaCO}_{3}$ (calcium carbonate, calcite) were determined by means of laser diffractometry through a CILAS 1064 laser particle analyzer. Analysis was carried out by dispersion of calcium carbonate in water, at $25^{\circ} \mathrm{C}$ over the range from 0.04 to $500 \mu \mathrm{m}$. The data for $\mathrm{CaCO}_{3}$ particle sizes were presented by the cumulative distribution as a function of particle size.

\subsection{Fluid preparation}

Xanthan gum $(4.3 \mathrm{~g} / \mathrm{L})$ was used as rheological modifier in all formulations, and solubilized in $350 \mathrm{~mL}$ of $57 \mathrm{~g} / \mathrm{L}$ sodium chloride aqueous solution for 24 hours, under constant stirring. Next, CMC and calcium carbonate were added to the polymer solution using a Hamilton Beach mixer, at 18,000 rpm. CMC and calcium carbonate were added separately and the mixing time for each product was 10 minutes. Twelve formulations were prepared and evaluated in regard to rheological behavior and filtrate volume. Table 1 shows the formulations studied.

\subsection{Viscosity tests}

A FANN model 35 A rotational viscometer was used to measure the viscosity of the colloidal suspensions. Its design includes a R1 Rotor sleeve, B1 Bob, F1 Torsion Spring, and a stainless steel sample cup for testing according to American Petroleum Institute Recommended Practice for Field Testing Water Based Drilling Fluids, API RP 13B-1/ISO 10414-1 Specification ${ }^{[24]}$. Rheological analysis of each fluid was carried out under six different shear rates $\left(5,10,170,340,511,1022 \mathrm{~s}^{-1}\right)$, at $25^{\circ} \mathrm{C}$. All the experiments were carried out in triplicate.

\subsection{Filtration properties}

The filterability tests were performed in triplicate with a Whatman paper filter (Number 50), in a stainless-steel filtration cell under constant pressure of $100 \mathrm{psi}$, at $25^{\circ} \mathrm{C}$, for 30 minutes. This procedure was used to replicate the testing conditions of API fluid -loss testing ${ }^{[24]}$. Error bars represented the standard error of the mean.

Both rheological and filtration characterization followed the recommendations of the American Petroleum Institute - RP $13 \mathrm{~B}^{[24]}$.

\subsection{Zeta potential}

Zeta potential $(\zeta)$ was determined in a Zeta Potential Analyzer (Brookhaven, New York, NY, USA). Electrophoretic mobilities of particles were measured by the analyzer and converted to zeta potential using the Smoluchowski Equation. The experiments were performed at $25^{\circ} \mathrm{C}$ with an equilibrium time of 24 hours for formulations F4 to F12. However, to better understand the interactions between calcium carbonate and $\mathrm{CMC}$, neither xanthan gum nor $\mathrm{NaCl}$ was added. The suspensions were prepared by previous solubilization of CMC $(8.5 \mathrm{~g} / \mathrm{L})$ in distilled water for 12 hours followed by addition of calcium carbonate $(57 \mathrm{~g} / \mathrm{L})$, with continue stirring for more 12 hours. $\zeta$ values were reported with an experimental error of less than 5\% (after 10 runs).

\section{Results and Discussion}

\subsection{Influence of CMC chemical structure and $\mathrm{CaCO}_{3}$ particle size on rheological properties}

Figure 1 shows that rheological properties depend strongly on the composition of the fluids. The fit of the power law model (Equation 1) to the rheological data was very good, with correlation coefficients $\left(R^{2}\right)$ close to 1 (results not shown). The behavior index $(n)$ indicated typical pseudoplastic fluid values in the 0.47 to 0.57 range, and the consistency index varied from 346 Pa.s ${ }^{\mathrm{n}}(\mathrm{F} 3)$ to $1399 \mathrm{~Pa}_{\mathrm{S}} \mathrm{s}^{\mathrm{F}}(\mathrm{F} 5)$.

$$
\tau=K(\dot{\gamma})^{n}
$$

where: $\tau=$ Shear stress $(\mathrm{Pa}) ; \dot{\gamma}=$ Shear rate $\left(\mathrm{s}^{-1}\right) ; K=$ Consistency index $\left(\mathrm{Pa} . \mathrm{S}^{\mathrm{n}}\right) ; n=$ Behavioral index.

\subsubsection{Effect of Mw and DS of carboxymethylcellulose}

Figure 2 shows the viscosity curves of F1 to F3. A significant decrease in viscosity and in consistency index (data not shown) was observed from F1 to F3. The rheological properties were greater for fluid F1 containing CMC with a higher $\mathrm{Mw}\left(\mathrm{Mw}=2.5 \times 10^{5} \mathrm{~g} / \mathrm{mol}\right)$ and lower $\mathrm{DS}(\mathrm{DS}=0.7)$. With an increase in $\mathrm{Mw}$, the polymer hydrodynamic volume also rises, leading to higher viscosity. On the other hand, an

Table 1. Composition of colloidal suspensions.

\begin{tabular}{|c|c|c|c|c|c|c|c|c|c|c|c|c|}
\hline \multirow{2}{*}{ Additive (g/L) } & \multicolumn{12}{|c|}{ Formulations } \\
\hline & F1 & F2 & F3 & F4 & F5 & F6 & F7 & F8 & F9 & F10 & F11 & F12 \\
\hline Xanthan gum & 4.3 & 4.3 & 4.3 & 4.3 & 4.3 & 4.3 & 4.3 & 4.3 & 4.3 & 4.3 & 4.3 & 4.3 \\
\hline $\mathrm{CMC} \mathrm{Mw}=2.5 \times 10^{5} ; \mathrm{DS}=0.7$ & 8.5 & & & 8.5 & 8.5 & 8.5 & & & & & & \\
\hline $\mathrm{CMC} \mathrm{Mw}=2.5 \times 10^{5} ; \mathrm{DS}=1.2$ & & 8.5 & & & & & 8.5 & 8.5 & 8.5 & & & \\
\hline $\mathrm{CMC} \mathrm{Mw}=0.9 \times 10^{5} ; \mathrm{DS}=0.7$ & & & 8.5 & & & & & & & 8.5 & 8.5 & 8.5 \\
\hline $\mathrm{CaCO}_{3} \mathrm{~A}$ & & & & 57 & & & 57 & & & 57 & & \\
\hline $\mathrm{CaCO}_{3} \mathrm{~B}$ & & & & & 57 & & & 57 & & & 57 & \\
\hline $\mathrm{CaCO}_{3} \mathrm{C}$ & & & & & & 57 & & & 57 & & & 57 \\
\hline $\mathrm{NaCl}$ & 57 & 57 & 57 & 57 & 57 & 57 & 57 & 57 & 57 & 57 & 57 & 57 \\
\hline
\end{tabular}


increase in DS can reduce $\mathrm{CMC}$ solubility in brine, thereby reducing viscosity. An increase in DS typically causes a more homogeneous distribution of carboxylate in the polymer chain ${ }^{[1]}$. Thus, immediate interactions may occur between salt and the polymer carboxylate groups, effectively shielding the anionic charge and inhibiting hydrogen bonds between the anionic sites and water molecules, diminishing polymer solubility in water.

\subsubsection{Effect of $\mathrm{CaCO}_{3}$ particle size}

The viscosity of non-Newtonian fluids is affected by the characteristics of the dispersed solid phase, such as particle shape, concentration and dimension, solid/liquid phase interactions, nature of the surface, particle size distribution, etc $^{[25]}$. Particle size distribution, uniformity factor and specific surface area are important physical parameters affecting fluids rheological and filtration behavior. It is clear that narrow and wide size distributions have different influences upon $\mathrm{CaCO}_{3}$ particles properties. A wider particle size distribution increases packing density and decreases aqueous medium demand, while a narrower particle size distribution gives higher hydration rates for equal specific surface area. It is obvious that as the particle size increases the surface area decreases. Likewise, CMC Mw and DS influence directly the degree of calcium carbonate particle flocculation.

As illustrated in Figures 3 to 5, after the addition of different samples of calcium carbonate to the fluids, almost all formulations experienced an increase in rheological properties (F4-F5-F6, compared to F1; F7-F8-F9, compared to F2 and F10-F11-F12, compared to F3).

This effect might be explained by polyelectrolyte adsorption onto the calcium carbonate surface, which is responsible for the increase in apparent particle volume, as well as higher mineral stability in the medium. On the other hand, the presence of a low number of small calcium carbonate particles can act as a lubricant, improving large particle rotation (smaller particles are interspersed between larger particles), leading to a reduction in viscosity ${ }^{[25,26]}$. This last effect could explain the results of formulation F12 (Figure 5), in which the CMC with the smallest Mw was used. In F12, viscosity declined from 250 to $200 \mathrm{cP}$ at a shear rate of $10 \mathrm{~s}^{-1}$. However, unlike the rheological behavior exhibited by F12, the other formulations show no decrease in viscosity in the presence of small calcium carbonate particles. This effect was likely mitigated by the strong contribution of CMC Mw and DS that altered the particles' attractive forces, responsible for controlling the state of dispersion and rheological properties of the fluids.

Table 2 shows the particle size of the $\mathrm{CaCO}_{3}$ used. The calcium carbonate samples exhibited a particle size in the range of 0.87 to $17.88 \mu \mathrm{m}, 1.39$ to $22.06 \mu \mathrm{m}$ and 1.92 to $32.65 \mu \mathrm{m}$ for calcium carbonate $\mathrm{A}, \mathrm{B}$ and $\mathrm{C}$, respectively, with mean particle sizes of $7.64 \mu \mathrm{m}, 12.27 \mu \mathrm{m}$ and $18.61 \mu \mathrm{m}$, for A, B and C, respectively. These values are in agreement with the manufacturer's data. In addition, calcium carbonate A showed the lowest average diameter and largest particle diameter distribution, which means significant amounts of different particle sizes, whereas calcium carbonate $\mathrm{B}$ and $\mathrm{C}$ displayed the narrowest diameter distribution.

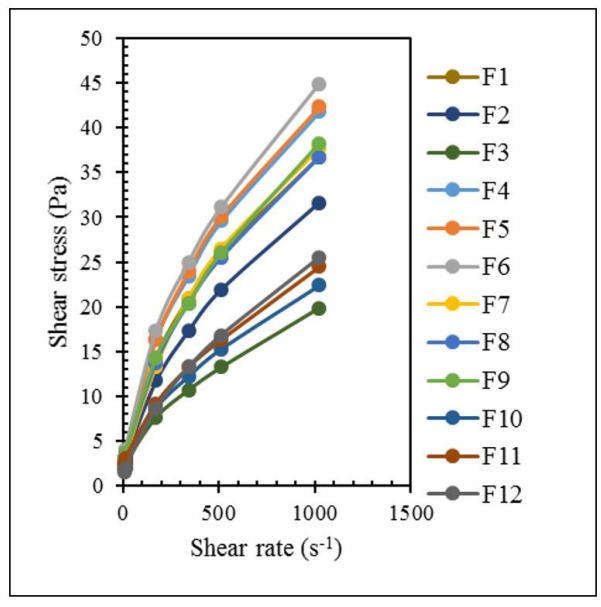

Figure 1. Flow curves of the colloidal suspensions described in Table 1, from shear rate 5 to $1022 \mathrm{~s}^{-1}$, at $25^{\circ} \mathrm{C}$.

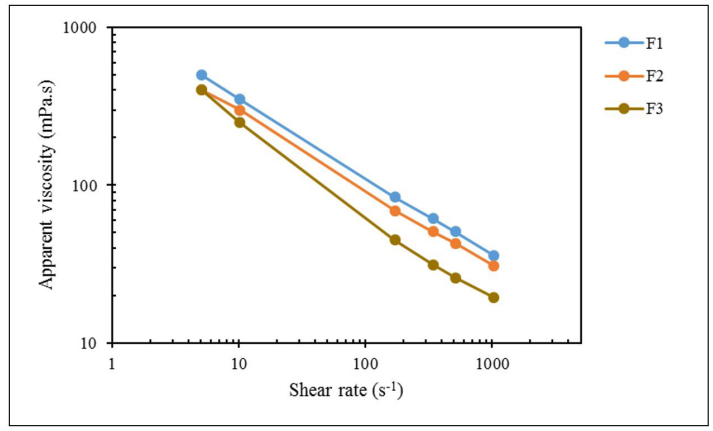

Figure 2. Viscosity curves for F1, F2 and F3 colloidal suspensions described in Table 1, from shear rate 5 to $1022 \mathrm{~s}^{-1}$, at $25{ }^{\circ} \mathrm{C}$. $\mathrm{F}=$ Formulation

Table 2. Particle size characterization of $\mathrm{CaCO}_{2} \mathrm{~A} ; \mathrm{B}$ and $\mathrm{C}$.

\begin{tabular}{lcccc}
\hline & $\begin{array}{c}\text { Average } \\
\text { diameter } \\
(\boldsymbol{\mu} \mathbf{m})\end{array}$ & $\begin{array}{c}\text { Diameter } \\
\text { at 10\% } \\
(\boldsymbol{\mu} \mathbf{m})\end{array}$ & $\begin{array}{c}\text { Diameter } \\
\text { at 50\% } \\
(\boldsymbol{\mu m})\end{array}$ & $\begin{array}{c}\text { Diameter } \\
\text { at 90\% } \\
(\boldsymbol{\mu m})\end{array}$ \\
\hline $\mathrm{CaCO}_{3} \mathrm{~A}$ & 7.64 & 0.87 & 5.56 & 17.88 \\
$\mathrm{CaCO}_{3} \mathrm{~B}$ & 12.27 & 1.39 & 12.40 & 22.06 \\
$\mathrm{CaCO}_{3} \mathrm{C}$ & 18.61 & 1.92 & 18.77 & 32.65 \\
\hline
\end{tabular}

$\mathrm{CaCO}_{3} \mathrm{C}$ was the carbonate sample that contributed least to the increase in the consistency index. The effect on the flux behavior of colloidal suspensions was more marked in the viscosity results obtained when $\mathrm{CMC}$ with the lowest $\mathrm{Mw}$ was used (Figure 5), especially at low shear rates. On the other hand, the rheological properties were very similar in the formulations in which $\mathrm{CaCO}_{3} \mathrm{~A}$ and $\mathrm{CaCO}_{3} \mathrm{~B}$ were used. This means that an increase in $\mathrm{CaCO}_{3}$ granulometry leads to fewer interactions between colloidal particles.

\subsection{Influence of CMC chemical structure and $\mathrm{CaCO}_{3}$ particle size on filtrate loss}

Figure 6 summarizes the influence of CMC Mw, DS and calcite granulometry on the filtrate volume of colloidal calcite suspensions. 


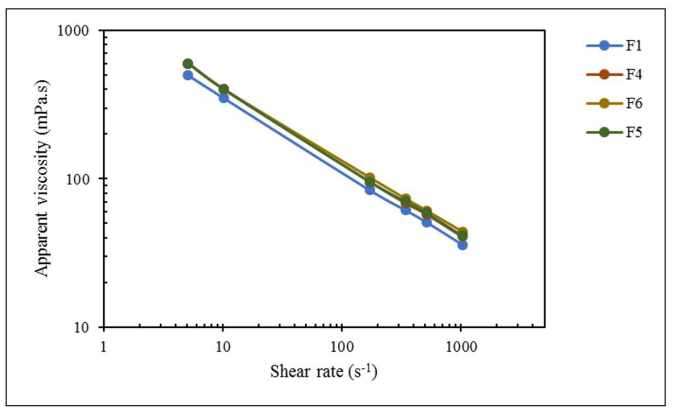

Figure 3. Viscosity curves for F1, F4, F5 and F6 colloidal suspensions described in Table 1, from shear rate 5 to $1022 \mathrm{~s}^{-1}$, at $25^{\circ} \mathrm{C} . \mathrm{F}=$ Formulation.

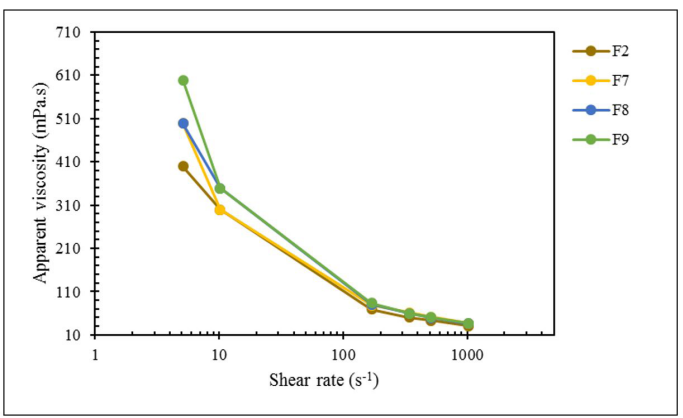

Figure 4. Viscosity curves for F2, F7, F8 and F9 colloidal suspensions described in Table 1 , from shear rate 5 to $1022 \mathrm{~s}^{-1}$, at $25^{\circ} \mathrm{C} . \mathrm{F}=$ Formulation.

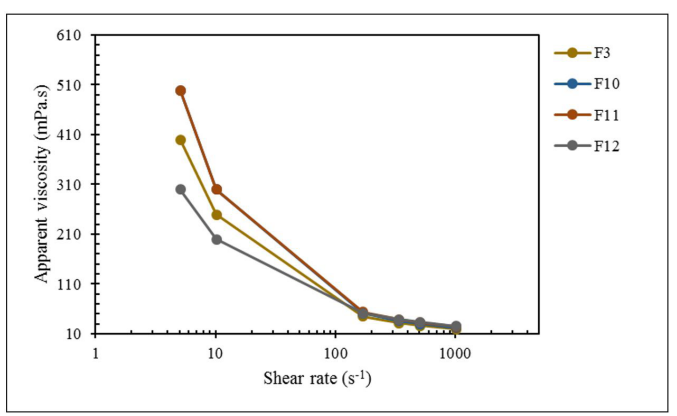

Figure 5. Viscosity curves for F3, F10, F11 and F12 colloidal suspensions described in Table 1, from shear rate 5 to $1022 \mathrm{~s}^{-1}$, at $25^{\circ} \mathrm{C} . \mathrm{F}=$ Formulation.

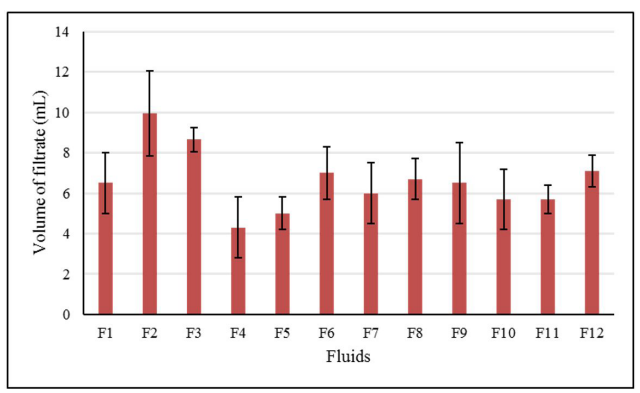

Figure 6. Filtrate volume of colloidal calcite suspensions, at constant pressure of $100 \mathrm{psi}, 25^{\circ} \mathrm{C}$, for $30 \mathrm{~min}$.

\subsubsection{Effect of CMC}

CMC is a water soluble organic colloid. As such, small amounts of CMC can significantly enhance water viscosity. On the other hand, filtrate volume decreases with an increase in filtrate viscosity. Another important parameter in the filtration process is the permeability of the cake formed on the surface of the filter paper. The filtrate volume decreases when filter cake permeability declines ${ }^{[27]}$. Among F1, F2 and F3 formulations, F1 showed the highest viscosity (Figure 2) and lowest filtrate volume (Figure 6) corroborating, thus, with the equation showed by Darley and Gray ${ }^{[27]}$, which evidences that the decrease of viscosity leads to an enhancement of filtrate volume. Besides, a small difference was observed between the filtrate volume of F2 and F3. There seems to be a critical polymer hydrodynamic volume that depends on $\mathrm{CMC} \mathrm{Mw}$ and DS, above which the filtrate volume decreases as a response to filtrate viscosity and filter cake permeability. In the presence of salt, the effect of increasing DS is similar to that of decreasing Mw, due to the enhanced polymer collapse at a high DS.

\subsubsection{Effect of the interaction between CMC and calcium carbonate}

The dispersion of calcium carbonate is important for its surface charge and colloidal properties as well as for its interaction with polymers ${ }^{[16]}$. The presence of water-soluble polysaccharides promotes interactions with calcium carbonate that reinforce the filter cake formed during filtration and provides the desired rheological properties over large temperature ranges. It has been reported that the calcium carbonate isoelectric point (iep) should lie within the range of $\mathrm{pH} 8.0-9.5^{[28]}$. CMC is in free acid form at $\mathrm{pH} 3.5$, and the acid groups are ionized (negatively charged) at about $\mathrm{pH}$ 7.0. This suggests that $\mathrm{CMC}$ may shift the $\mathrm{CaCO}_{3}$ iep in solution, affecting charge development at the interface. This agrees with findings by Wang and Somasundaran ${ }^{[29]}$, which showed that $\mathrm{CMC}$ was responsible for the decreased zeta potential of talc with a rise in the iep from $\mathrm{pH} 2.5$ to $\mathrm{pH}$ 3.5. This evidence suggests that electrostatic interactions play an important role in the adsorption process of $\mathrm{CMC}$ onto $\mathrm{CaCO}_{3}$ and, consequently, in filtrate control. Figure 6 shows that $\mathrm{CMC}$ is responsible for the significant influence on filtrate control in association with calcium carbonate. The affinity of CMC molecules with dispersed calcium carbonate particles depends on the available $\mathrm{Ca}^{2+}$ surface sites for polymer adsorption. It should be noted that not only polymer and $\mathrm{CaCO}_{3}$ structure influence adsorption kinetics, but also the ionic strength of the medium. Several investigators ${ }^{[30]}$ have reported that the adsorption of smaller CMC chains prevails at low salt concentrations (for example: $0.01 \mathrm{M}$ ) due to their faster diffusion. In other words, these smaller polyectrolytes create an electrostatic barrier that opposes the arrival of larger molecules ${ }^{[29]}$. However, in our case, a salt concentration of $1 \mathrm{M}$ was used in all formulations. The lowest filtrate volume values (F4-F5) were mainly associated with the highest $\mathrm{CMC} \mathrm{Mw}\left(2.5 \times 10^{5} \mathrm{~g} / \mathrm{mol}\right)$. The electrostatic barrier collapse caused by "salt screening" causes the larger charged macromolecules to reach the calcium carbonate surface ${ }^{[16]}$. Moreover, it is reasonable to assume that the greater the interactions between CMC and Lewis acid sites on the calcium carbonate for the formation of $\mathrm{CMC}-\mathrm{Ca}^{2+}$ complexes, the faster the adsorption process 
Table 3. Zeta potential of $\mathrm{CaCO}_{3} / \mathrm{CMC}$ colloidal suspensions.

\begin{tabular}{|c|c|c|c|c|c|c|c|c|c|}
\hline \multirow{2}{*}{$\begin{array}{c}\text { Additive } \\
\mathrm{CMC} \mathrm{Mw}=2.5 \times 10^{5} ; \mathrm{DS}=0.7\end{array}$} & \multicolumn{9}{|c|}{ Concentration $(\mathrm{g} / \mathrm{L})$} \\
\hline & 8.5 & 8.5 & 8.5 & & & & & & \\
\hline $\mathrm{CMC} \mathrm{Mw}=2.5 \times 10^{5} ; \mathrm{DS}=1.2$ & & & & 8.5 & 8.5 & 8.5 & & & \\
\hline $\mathrm{CMC} \mathrm{Mw}=0.9 \times 10^{5} ; \mathrm{DS}=0.7$ & & & & & & & 8.5 & 8.5 & 8.5 \\
\hline $\mathrm{CaCO}_{3} \mathrm{~A}$ & 57 & & & 57 & & & 57 & & \\
\hline $\mathrm{CaCO}_{3} \mathrm{~B}$ & & 57 & & & 57 & & & 57 & \\
\hline $\mathrm{CaCO}_{3} \mathrm{C}$ & & & 57 & & & 57 & & & 57 \\
\hline$\zeta(\mathrm{mV})$ & -11.95 & -4.82 & -13.01 & -19.02 & -34.00 & -36.09 & -41.20 & -14.51 & +27.12 \\
\hline
\end{tabular}

and, consequently, the lower the filtrate volume. This effect contributed to the decline in filtrate volume for F7-F8-F9, compared to F2, due to the higher DS of CMC.

\subsubsection{Effect of $\mathrm{CaCO}_{3}$ particle size}

Understanding the filtration mechanism that allows the establishment of an association between calcium carbonate particle size and the filtration properties of water-based drilling fluids is a daunting challenge in elucidating the problems related to fluid loss in wellbores. According to the results obtained (Figure 6), the formulations with the largest average calcium carbonate particle size $(18.61 \mu \mathrm{m})$ exhibited the highest filtrate volume, caused by formation of a higher permeability filter cake. At the beginning of filtration, the colloidal suspension invades the porous medium (spurt loss). The suspended solids attempt to flow with the liquid stream, but a fraction of these particles bridge the pores and begin to build a filter cake. Finer particles fill the interstices left by the bridging particles and ultimately form such a tight matrix that only liquid (filtrate) can penetrate. Once this filter cake is established, the flow rate of fluid into the porous medium is dictated by the permeability of the cake ${ }^{[27]}$. Thus, in addition to average particle size, another important parameter is particle size distribution. Table 2 shows that $\mathrm{CaCO}_{3} \mathrm{~A}$ has the widest diameter distribution curve, with particles of different sizes, while $\mathrm{CaCO}_{3} \mathrm{~B}$ and $\mathrm{CaCO}_{3} \mathrm{C}$ have narrower curves. The results in Figure 6 demonstrate that $\mathrm{CaCO}_{3} \mathrm{~A}$, with the smallest average diameter particle and widest diameter distribution curve, was more effective in controling filtrate volume, producing a low-permeability filter cake.

\subsection{Influence of CMC chemical structure and $\mathrm{CaCO}_{3}$ particle size on zeta potential}

Zeta potential $(\zeta)$ provides an indirect measurement of surface charge density and is a relative indicator of system stability. The electrical properties of the calcium carbonate/CMC interface were investigated in order to elucidate the mechanisms that dictate charging behavior at the solid-liquid interface and, consequently, improve understanding of the electrochemical double layer (EDL) in the shear plane between the $\mathrm{CaCO}_{3}$ particle surface and counterions near the surface and surrounding polymeric fluid. Table 3 shows the zeta potential of the colloidal suspensions as a function of $\mathrm{CaCO}_{3}$ granulometry and $\mathrm{CMC}$ structural properties.

For all calcite suspensions studied, $\zeta$ was negative and increased with a rise in DS for CMC Mw $2.5 \times 10^{5}$. This means a higher amount of anionic charges in the medium, probably due to complete cationic calcite surface saturation by the polymer, which was more effective with the increase in DS. When CMC with Mw 0.9 x $10^{5}$ and DS 0.7 was used, different tendencies were observed, depending on the calcite employed. With an increase in calcite particle diameter, the negative $\zeta$ value became positive, probably due to incomplete saturation of the cationic calcite surface by CMC.

According to the zeta potential, good stability would be expected for all calcite suspensions, owing to the ionic charges on the surface. However, calcite particles with an anionic surface suggest CMC adsorption, which could lead to higher viscosities for the suspensions and the formation of low-permeability cakes during filtration. In this scenario, the formulation with the lowest negative zeta potential (F5) could lead to a more associative interaction between the particles and a more cohesive cake, resulting in high viscosity fluid and low filtrate volume, as depicted in Figures 3 and 6.

\section{Conclusions}

In this study, we investigated the effect of calcite particle size associated with CMC Mw and DS on the rheological and filtration properties of the aqueous suspensions, considering the general conditions used in drilling fluids. Zeta potential data were also used to clarify the interactions between calcite and CMC.

The higher Mw $\left(2.5 \times 10^{5} \mathrm{~g} / \mathrm{mol}\right)$ and lower DS (0.7) of CMC contributed to both higher viscosity and lower filtrate volume. This effect was improved in the presence of calcite, providing important evidence of $\mathrm{CMC}-\mathrm{CaCO}_{3}$ interactions. In addition, the use of a calcite sample with low average particle size but wide size distribution can contribute significantly to reducing filtrate loss across a porous medium. The zeta potential results provide even more evidence of the effective interactions between calcite and CMC. Lower negative zeta potential values were obtained for the suspensions containing higher CMC Mw $\left(2.5 \times 10^{5} \mathrm{~g} / \mathrm{mol}\right)$, lower DS CMC (0.7), and small calcite particle size. These results corroborate the rheological and filtration properties. In summary, the results of this paper indicate that the effectiveness of $\mathrm{CMC}-\mathrm{CaCO}_{3}$ (calcite) in the control of filtrate loss is related to good interaction between anionic groups of CMC and Lewis acid sites on the surface of the mineral and that this can be enhanced by proper selection of $\mathrm{CMC}$ and $\mathrm{CaCO}_{3}$.

\section{Acknowledgements}

The authors are grateful to Professor Hugo Alexandre de Oliveira Rocha from the Biochemistry Department of the Federal University of Rio Grande do Norte (UFRN) for his 
help in zeta potential analysis, and to CAPES (Coordination for the Improvement of Higher Education Personnel) and Petrobras for financial support.

\section{References}

1. Caraschi, J. C., \& Campana, S. P. F. (1999). Influência do grau de substituição e da distribuição de substituintes sobre as propriedades de equilíbrio de carboximetilcelulose em solução aquosa. Polimeros: Ciência e Tecnologia, 9(2), 70-77. http:// dx.doi.org/10.1590/S0104-14281999000200015.

2. Antti, G., Pentti, P., \& Hanna, K. (2008). Ultrasonic degradation of aqueous carboxymethylcellulose: effect of viscosity, molecular mass, and concentration. Ultrasonics Sonochemistry, 15(4), 644-648. http://dx.doi.org/10.1016/j.ultsonch.2007.09.005. PMid: 17986397.

3. Britto, D., \& Assis, O. B. G. (2009). Thermal degradation of carboxymethylcellulose in different salty forms. Thermochimica Acta, 494(1-2), 115-122. http://dx.doi.org/10.1016/j. tca.2009.04.028.

4. Siqueira, E. J., Brochier Salon, M.-C., \& Mauret, E. (2015). The effects of sodium chloride $(\mathrm{NaCl})$ and residues of cellulosic fibres derived from sodium carboxymethylcellulose ( $\mathrm{NaCMC}$ ) synthesis on thermal and mechanical properties of CMC films. Industrial Crops and Products, 72, 87-96. http://dx.doi. org/10.1016/j.indcrop.2015.01.017.

5. Wang, W., \& Wang, A. (2010). Nanocomposite of carboxymethyl cellulose and attapulgite as a novel $\mathrm{pH}$-sensitive superabsorbent: Synthesis, characterization and properties. Carbohydrate Polymers, 82(1), 83-91. http://dx.doi.org/10.1016/j.carbpol.2010.04.026.

6. Grządka, E. (2011). Competitive adsorption in the system: carboxymethylcellulose/surfactant/electrolyte $/ \mathrm{Al}_{2} \mathrm{O}_{3}$. Cellulose, 18(2), 291-308. http://dx.doi.org/10.1007/s10570-010-9489-4.

7. Ueno, T., Yokota, S., Kitaoka, T., \& Wariishi, H. (2007). Conformational changes in single carboxymethylcellulose chains on a highly oriented pyrolytic graphite surface under different salt conditions. Carbohydrate Research, 342(7), 954-960. http://dx.doi.org/10.1016/j.carres.2007.01.017. PMid: 17316582

8. Gibis, M., Schuh, V., Allard, K., \& Weiss, J. (2017). Influence of molecular weight and degree of substitution of various carboxymethyl celluloses on unheated and heated emulsion-type sausage models. Carbohydrate Polymers, 159, 76-85. http:// dx.doi.org/10.1016/j.carbpol.2016.12.012. PMid:28038756.

9. Li, Z., Wang, Y., Pei, Y., Xiong, W., Xu, W., Li, B., \& Li, J. (2017). Effect of substitution degree on carboxymethylcellulose interaction with lysozyme. Food Hydrocolloids, 62, 222-229. http://dx.doi.org/10.1016/j.foodhyd.2016.07.020.

10. Mohammadi, M., Sadeghnia, N., Azizi, M., Neyestani, T., \& Mortazavian, A. M. (2014). Development of gluten-free flat bread using hydrocolloids: Xanthan and CMC. Journal of Industrial and Engineering Chemistry, 20(4), 1812-1818. http://dx.doi.org/10.1016/j.jiec.2013.08.035.

11. Wahid, R., Holt, R., Hjorth, R., \& Scorza, F. B. (2016). Chemistry, manufacturing and control (CMC) and clinical trial technical support for influenza vaccine manufacturers. Vaccine, 34(45), 5430-5435. http://dx.doi.org/10.1016/j.vaccine.2016.07.046. PMid:27484011.

12. Ernsting, M. J., Tang, W. L., Maccallum, N. W., \& Li, S. D. (2012). Preclinical pharmacokinetic, biodistribution, and anticancer efficacy studies of a docetaxel-carboxymethylcellulose nanoparticle in mouse models. Biomaterials, 33(5), 14451454. http://dx.doi.org/10.1016/j.biomaterials.2011.10.061. PMid:22079003.

13. Seid, K. A., Badot, J. C., Dubrunfaut, O., Levasseur, S., Guyomard, D., \& Lestriez, B. (2012). Influence of the carboxymethyl cellulose binder on the multiscale electronic transport in carbon- $\mathrm{LiFePO}_{4}$ nanocomposites. Journal of
Materials Chemistry, 22(45), 24057-24066. http://dx.doi. org/10.1039/c2jm34964g.

14. Zhang, L., Sun, H., Han, B., Peng, L., Ning, F., Jiang, G., \& Chehotkin, V. F. (2016). Effect of shearing actions on the rheological properties and mesostructures of CMC, PVP and $\mathrm{CMC}+\mathrm{PVP}$ aqueous solutions as simple water-based drilling fluids for gas hydrate drilling. Journal of Unconventional Oil and Gas Resources, 14, 86-98. http://dx.doi.org/10.1016/j. juogr.2016.02.002.

15. Luz, R. C. S., Fagundes, F. P., \& Balaban, R. C. (2017). Water-based drilling fluids: the contribution of xanthan gum and carboxymethylcellulose on filtration control. Chemical Papers, 71(12), 2365-2373. http://dx.doi.org/10.1007/s11696017-0231-7.

16. Backfolk, K., Lagerge, S., Rosenholm, J. B., \& Eklund, D. (2002). Aspects on the Interaction between Sodium Carboxymethylcellulose and Calcium Carbonate and the Relationship to Specific Site Adsorption. Journal of Colloid and Interface Science, 248(1), 5-12. http://dx.doi.org/10.1006/ jcis.2001.8195. PMid:16290496.

17. Tso, C.-P., \& Shih, Y.-H. (2017). The influence of carboxymethylcellulose (CMC) on the reactivity of Fe NPs toward decabrominated diphenyl ether: The Ni doping, temperature, $\mathrm{pH}$, and anion effects. Journal of Hazardous Materials, 322(Pt A), 145-151. http://dx.doi.org/10.1016/j. jhazmat.2016.03.082. PMid:27083057.

18. Beaussart, A., Mierczynska-Vasilev, A., \& Beattie, D. A. (2010). Evolution of carboxymethyl cellulose layer morphology on hydrophobic mineral surfaces: Variation of polymer concentration and ionic strength. Journal of Colloid and Interface Science, 346(2), 303-310. http://dx.doi.org/10.1016/j.jcis.2010.03.008. PMid:20347097.

19. Laskowski, J. S., Liu, Q., \& O’Connor, C. T. (2007). Current understanding of the mechanism of polysaccharide adsorption at the mineral/aqueous solution interface. International Journal of Mineral Processing, 84(1-4), 59-68. http://dx.doi. org/10.1016/j.minpro.2007.03.006.

20. Moyo, F., Tandlich, R., Wilhelmi, B. S., \& Balaz, S. (2014). Sorption of Hydrophobic Organic Compounds on Natural Sorbents and Organoclays from Aqueous and Non-Aqueous Solutions: A Mini-Review. International Journal of Environmental Research and Public Health, 11(5), 5020-5048. http://dx.doi. org/10.3390/ijerph110505020. PMid:24821385.

21. Ganbaatar, N., Imai, K., Yano, T., \& Hara, M. (2017). Surface force analysis of glycine adsorption on different crystal surfaces of titanium dioxide (TiO2). Nano Convergence, 4(1), 38. http:// dx.doi.org/10.1186/s40580-017-0125-y. PMid:29264108.

22. Liu, Q., Zhang, Y., \& Laskowski, J. S. (2000). The adsorption of polysaccharides onto mineral surfaces: an acid/base interaction. International Journal of Mineral Processing, 60(3-4), 229-245. http://dx.doi.org/10.1016/S0301-7516(00)00018-1.

23. Wiśniewska, M., Urban, T., Grządka, E., Zarko, V. I., \& Gun'ko, V. M. (2014). Comparison of adsorption affinity of polyacrylic acid for surfaces of mixed silica-alumina. Colloid \& Polymer Science, 292(3), 699-705. http://dx.doi.org/10.1007/ s00396-013-3103-x. PMid:24610970.

24. American Petroleum Institute - API. (1997). Specification for oil-well drilling fluid materials. Dallas: API.

25. Shenoy, A. V. (1999). Rheology of filled polymer systems. Dordrecht: Springer. doi:http://dx.doi.org/10.1007/978-94015-9213-0

26. Shaheen, E. I. (1972). Rheological study of viscosities and pipeline flow of concentrated slurries. Powder Technology, 5(4), 245-256. http://dx.doi.org/10.1016/0032-5910(72)80027-5.

27. Darley, H. C. H., \& Gray, G. R. (1988). Composition and properties of drilling and completion fluids. Houston: Gulf Publishing Company. 
28. Somasundaran, P., \& Agar, G. E. (1967). The zero point of charge of calcite. Journal of Colloid and Interface Science, 24(4), 433-440. http://dx.doi.org/10.1016/0021-9797(67)90241-X.

29. Wang, J., \& Somasundaran, P. (2005). Adsorption and conformation of carboxymethyl cellulose at solid-liquid interfaces using spectroscopic, AFM and allied techniques. Journal of Colloid and Interface Science, 291(1), 75-83. http:// dx.doi.org/10.1016/j.jcis.2005.04.095. PMid:15907862.
30. Atkin, R., Craig, V. S. J., Wanless, E. J., \& Biggs, S. (2003). Mechanism of cationic surfactant adsorption at the solid-aqueous interface. Journal of Colloid and Interface Science, 103(3), 219-304. http://dx.doi.org/10.1016/S0001-8686(03)00002-2. PMid:12781966.

Received: Dec. 02, 2017

Revised: Mar. 19, 2018

Accepted: Mar. 26, 2018 